\title{
Exploration and Practice of "Chinese Culture Classics" in Colleges and Universities
}

\author{
Jun Yang ${ }^{1, a}$, Yuyang Zu ${ }^{2, b}$, Yuehui Wang ${ }^{1, a}$, Guangyang Wang, a , Yanping Gao, a, Shixin \\ $\mathbf{Y u} \mathbf{u}^{1, \mathbf{a}}$ \\ ${ }^{1}$ School of Education and Sports, Bohai University, Jinzhou, 121013, China \\ ${ }^{2}$ College of Foreign Languages, Bohai University, Jinzhou, 121013, China \\ a344530141@qq.com, b1143119122@qq.com
}

Keywords: Chinese Culture Classics; colleges and universities; practice

\begin{abstract}
Based on the current situation of "Chinese Culture Hot" and its impact on university campuses over recent years, this paper aims to guide "Chinese Culture" to develop healthily and continuously in students in colleges and universities, and analyzes the accomplishments of "Chinese Culture". For this purpose, "Five Conditions" activity model is created. The paper puts forward the "Chinese Culture Classics" learning activities should be based on the environment, activities serve as the carrier, the curriculum as the support, the construction of scientific research base as the starting point. It relies on various media on campus to give full play to the positive role of classical reading in undergraduates' ideological and moral education, campus culture construction and teacher training.
\end{abstract}

\section{Introduction}

In recent years, the whole society began to have imperious needs for "Chinese Culture ". Wuhan University, Renmin University of China and Xiamen University started "Chinese Culture" classes earlier. Subsequently, other universities, primary and middle schools also successively set up "Chinese Culture" classes or "Chinese Culture" courses. At present, all colleges and universities have started their waves of reading the "Chinese Culture Classics" articles, but most of them are superficial and show the disorderly and blindly status following the trend. They can not really make the classics reading based on the campus and the youth. In this study, we selected undergraduates from several universities in Liaoning Province as cases and conducted the questionnaire survey on 500 undergraduates from several universities in Liaoning Province. Combining with the hot issue of "Chinese Culture Classics", this study explores and practices the "Chinese Culture Classics" into colleges and universities.

\section{The definition of "Chinese Culture"}

The word of "Chinese Culture" comes from the historical period of eastward transmission of western sciences. The first man used the word "Chinese Culture" derives from Liang Qichao. In the autumn of 1902, Liang Qichao proposed to Huang Zunxian in his letter about the founding of the "Chinese Culture Journal", in order to "preserve the quintessence of the nation." A few months later, Liang Qichao wrote another article entitled "The Trend of Changes in Chinese Academic Thought", and repeatedly mentioned "Chinese Culture". Zhang Taiyan initiated the "Chinese Culture Class Seminar" in Tokyo in September 1906 and said: "The scholars are the sources of the establishment of the state..." ${ }^{[1]}$ The necessity of using the word "Chinese Culture" is obvious. In the year of 1906, the Quintessence party of Chinese Culture, Deng Shi, he wrote: "What is the Chinese Culture scholar? Which is the key leaning of the nation." ${ }^{[2]}$ Mr. Deng's concept of "Chinese Culture" is very broad and mainly emphasizes the practical utility of "Chinese Culture". Later, in the publication of the "Chinese Culture Quarterly", Hu Shi also defined the concept of "Chinese Culture": "All ancient cultural history in China is our national heritage. The study of all these ancient cultural histories is 
that of "Chinese heritage Culture", briefly known as "Chinese Culture". ${ }^{[3]}$ As for that year, the high status in academia of Hu Shi, so his point of view is the most widely affected. Most people now understand the concept of "Chinese Culture" mostly belongs to Hu Shi.

In the strict significence, so far, academia has not given us the unified and clear definition. "Chinese Culture" is a constantly evolving and substantial concept. However, the connotation of "Chinese Culture" has formed the consensus by default. Ji Baocheng, the advocater of Chinese Classics Institute and the president of Renmin University of China, believes that the generalized "Chinese Culture", that is, "all the ancient historical and cultural history of China" as Hu Shi said, includes ideological, academic, literary and fortune works; the Narrow "Chinese Culture" refers to the traditional ideology culture, it is the centre content of the "Chinese Culture", is the concentrated expression of the essential attributes of "Chinese Culture". ${ }^{[4]}$

This paper mainly discusses: "Chinese Culture", that is the narrow character. It is an academic aspect of Chinese traditional culture, and mainly refers to Chinese traditional philosophy, history, language and literature.

\section{Analysis of the "Chinese Culture" accomplishment of contemporary undergraduates}

Undergraduates are obscure about the concept of "Chinese Culture". Survey shows that only $5.5 \%$ of undergraduates are very clear about the content of it, most of them are liberal arts students; $50.6 \%$ of undergraduates generally understand it; $41.7 \%$ and $2.2 \%$ are unclear and unheard of "Chinese Culture" content. This shows that contemporary undergraduates for the concept of "Chinese Culture" is very obscure, even some students do not have the concept of "Chinese Culture". In the "Chinese Culture Classics" reading, only $3.1 \%$ of students completely read a "Chinese Culture Classics" book; 84.3\% of students said they did not read it completely, only have the approximate understanding; and $12.6 \%$ of the students said they never read "Chinese Culture Classics"books. ${ }^{[5]}$ Thus, it can be seen that contemporary undergraduates are in short consciousness of reading classical Chinese literature. "Chinese Culture" knowledge is extremely deficient, and the only relevant knowledge is fragmented, lacking the key points and also failing to form the complete knowledge system of "Chinese Culture".

Transmission mode of dilemma in "Chinese Culture". In the survey of the reasons for the "Chinese Culture Hot" among students, 37\% of the students said they are due to the guiding role of social media (like Lecture Room). As for "Lecture Room," such a "Chinese Culture Fast Food", even more than $90 \%$ of the students stand in favor of it. To sum up, the media's intervene, especially the appearance of "Chinese Culture Fast Food", really made the "Chinese Culture Hot". In the era of information explosion, students want to acquire knowledge in an efficient way by using straightforward and clear-cut "Chinese Culture Fast Food" instead of obscure self-reading.

Undergraduates' outlook on "Chinese Culture". For "Chinese Culture", 85.5\% of students are standing on the "like" level, but the ignorance of the "Chinese Culture" knowledge is reflected in the questionnaire. The ignorance is derived from the enthusiasm which needs to be reflected. In the question of whether "Chinese Culture" can provide the contemporary people with reliable belief and belief system", $26.1 \%$ of students said that they were completely sure, but $63.3 \%$ of students said they could not be sure. ${ }^{[6]}$ This shows that students in the world which filled with pluralistic values, have some adore of "Chinese Culture", but the more is doubtful and blind.

Undergraduates' understanding of the prospect of "Chinese Culture". For the prospects of the development of "Chinese Culture", only $10.6 \%$ of students think it is very glorious and bright; $51.7 \%$ of students think it is very difficult, we need to continue exploration for further development; $7.8 \%$ of students think it has no change; $28.8 \%$ of students think they will calm down after the suddenly "hot"; $1.1 \%$ of students think that "Chinese Culture" will eventually disappear. ${ }^{[7]}$ The data shows that most students are not optimistic about the development of "Chinese Culture".

Colleges and universities pay less attention to "Chinese Culture" education. Only 3.3\% of students think it is due to the government's attention and guidance in the investigation of the reasons why the "Chinese Culture Hot" appeared. This shows that in the promotion of "Chinese Culture", the government departments did not provide relevant policies and measures, resulting in "Chinese 
Culture" showed in a random and disorder status, and there is no formational concerted effort. In the survey on the most important source of knowledge of students in "Chinese Culture", 25\% chose school education, 53\% chose to self-study "Chinese Culture Classics" books, and 22\% chose from television broadcasting, the Internet and others. This shows that at present the main channel for students to acquire knowledge of "Chinese Culture" is books, the mass media and the Internet. ${ }^{[8]}$ And the most important traditional way is still reading books. No professional teaching materials, no special fund, resulting in the relatively weak links between colleges and universities.

Lack of relevant appraisal system. In the survey, $43.3 \%$ of the students believe that "'Chinese Culture" are in conflict with the time of learning foreign languages, computers, and natural sciences." Many students in the interviews also showed that they can skillfully read and write in English, but do not understand classical Chinese. Thus, under the examination-oriented education system, undergraduates have obvious utility pragmatism for knowledge learning. In the face of the social pressure of graduation employment, students choose to spend a lot of time learning English, computer or professional knowledge. Another $11.4 \%$ of the students think it is because lack of relevant appraisal system. This shows that in order to ensure "Chinese Culture" can promote the healthy and sustainable development into students and improving the mechanism construction is an inevitable reality project.

\section{Exploration and practice of "Chinese Culture Classics Reading" in colleges and universities}

Only establishing the model of long-term mechanism and practical learning, can make the "Chinese Culture Classics" base on the campus, base on the young people and increase their attractiveness, so as to provide powerful support for the "Chinese Culture Classics" reading activities in colleges and universities, so that they will not be formalized. For this purpose, we have created "Five Conditions" activity model.

\subsection{Create "Chinese Culture" education atmosphere based on the environment}

Propaganda department establish "'Chinese Culture" education advocacy board" in the school, "'Chinese Culture" education advocacy signs" "'Chinese Culture" education advocacy posters", replace the piece of "Chinese Culture Classics" on LED everyday, academy websites, broadcasting room, academy newspapers have carry out the relevant content special column. Creating the good atmosphere, not only can increase students knowledge of "Chinese Culture" and let students feel the deep classical culture accomplishment, at the same time, it also has become the beautiful sights to build up the campus culture.

\subsection{Activities as the carrier, make the "Chinese Culture" immerse students' physical and mental development}

Extracurricular activities and the life of the caucus are the extension of the main battleground of teaching. Teachers can use the huge space combining with the theme classes, groups and students association activities, and bring "Chinese Culture Classics" into students cultural quality education and campus culture construction system. In addition, teachers should emphasize the innovation of methods and ways, follow the rules and characteristics of physical and mental development of students during their ages, sufficiently mobilize the initiative and enthusiasm of students, exchange "want me to read" to "I want to read" and cultivate "enjoy classics, read classics" habits. Schools should carry out reading performance competitions, calligraphy and painting exhibitions and artistic activities. In addition, classical poetry reading should be more exciting through artistic forms such as dance, music, and poetry reading by new rhyme. At the same time, we can also hold campus "Chinese Culture Classics" traditional culture propaganda month, together with the assosiation culture, establish classical poetry reading association and so on. Around the outstanding traditional culture, a series of publicity and education activities are carried out. In this way, even undergraduates can further comprehend the charm of classical poetry in the course from their activities, spread outstanding traditional culture to the society and play a role in radiating and 
influencing society.

\section{Curriculum as the support, let classical reading enter the university class}

Nomal universities or Chinese majors should open relevant compulsory courses. "Great learning makes a teacher, moral integrity makes a model" is the educational thought of normal colleges and universities, and popularizing Chinese outstanding traditional culture is an important channel for teaching education. Therefore, in terms of curriculum, normal universities or Chinese major professionals should take Chinese traditional culture as an important part of their compulsory courses and strengthen their classical reading so as to make the "Chinese Culture Classics" reading become a compulsory course for students. In addition, teachers should cultivate a group of elites, making them be the backbone to force driving the improvement of the overall standard in the campus.

Increase the content of classical readings in College Chinese, and also add the famous modern and contemporary articles with the national spirit and the traditional Chinese virtues, so that students are based on learning and absorbing the essence of the "Chinese Culture Classics", improving their own language and culture accomlishment. ${ }^{[9]}$ We can set up optional classes such as classical reading and traditional Chinese culture, or invite famous experts to offer classical appreciation lectures and trainings to supplement and improve the humanistic accomplishment and language standard of students.

\section{Construction of scientific research base as the starting point, achieve sustainable and healthy development of classical reading}

Write characteristic textbooks and reference books. In order to obsorb "Chinese Culture Classics" reading into the training objectives, the schools need to adjust their current curriculum and teaching skill training programs. Existed teaching materials should enrich and emphasize the characteristics of classical reading, speaking and writing. Choosing from existed professional teaching materials such as College Chinese and History of Literature works, etc. Schools in different regions can also select existed textbooks that meet the requirements or write charateristic textbooks and reference books according to their actual needs.

Strengthen the construction of the "Chinese Culture Classics" teaching staff. Since the formal establishment of "Chinese Culture Classics", new requirements have been put on teachers. Therefore, the schools should cultivate teachers with high professional ethics, nice language accomplishment, excellent educating skills, good moral integrity, they are dedicated to work and undertaking the work of teaching and tutoring classical Chinese poems. From national to local, backbone teachers should be trained at all levels to play the role of trainees in leading and demonstrating activities and conducting relevant seminars so as to constantly sum up gains and losses and promote the effective development of classical reading.

Construct "Chinese Culture Classics" reading resource database. In order to carry out the teaching of classical reading and its activities in a high-quality and efficient way, provide the exchange platform, and talents and intellectual support for this purpose, the school should set up a database of famous classical readings and famous classical experts in colleges and universities. The establishment of the two databases will be the fundamental guarantee for effectively promoting the healthy and sustainable development of classical reading in colleges and universities.

\section{Relying on the various media in the campus, set up carriers and extensively build platform}

In today's media society, endless variety of new media, continuous change and innovation, the effective use of various (campus) media, combined with the characteristics of students and the characteristics of different universities carry out and spread the classical reading activities, which are good ways and methods. Firstly, expand the classical reading field in colleges and universities. It can set up the carrier in various ways and set up the broad platform to regularly broadcast relevant 
classical poems, images and competitions on the campus broadcasting room, TV stations, campus websites, school newspapers, blackboard painting; use QQ, Renren, Weibo, WeChat and other new media, widely carry out communication between the teachers and students, students and students. Secondly, enrich the activities of classical reading activities. According to different types of schools, different majors, different grades of students characteristics, hierarchically organise the classical reading activities.

\section{Conclusions}

As the carrier of national spirit, "Chinese Culture" plays an important role in the task of effectively realizing students' national culture identity. The construction of the "Five Conditions" model extrude to integrate the content of "Chinese Culture Classics" into resources such as curriculum, activities, environment and platform, and has diversified and situational cultivated students from many factors such as goals, contents, ways, means, and environment. The combination of "Chinese Culture" education and talents training model innovation, which coincides with the training objectives of fully training high-quality professionals and entrepreneurial accomplishments in colleges and universities. Give priority to education, this is "Chinese Culture Classics" into colleges and universities, that is, the innovation and reform of talents training mode.

\section{Acknowledgements}

Economy and social development project in Liaoning in 2018: Reseach on the Cultivation of the Pedagogical Education Core Accomplishmet under the Background of Supply-side Structural Reform(2018LSLKTYB-004); "China's 13th plan of five-year national development" of Education and Science Project in Liaoning in 2017: Exploration and Practice of "Chinese Culture Classics" into Colleges and Universities(JG17DB013); National Undergraduate Training Program for Innovation and Entrepreneurship in 2017: Exploration and Practice of "Chinese Culture Classics" into Colleges and Universities(2017101670003); Postgraduate education and teaching reform project of Bohai University in 2016: Action Reaserch on the Cultivation Model of "Advanced ability"-Oriented Primary Education Master Professional Talents Reform; This work is supported by Teaching Reform Project of Bohai university in 2015(BDJG-15-YB-B-012).

\section{References}

[1] Liu Shizhen, Hong Zongli, Mother Language Curriculum Standard at Home and Abroad[Z]. Nanjing: Jiangsu Education Publishing House, 2000.

[2] Ni Wenjin, Ouyang Ruying. Prospect of Chinese Education[M]. Shanghai: East China Normal University Publishing House, 2000.

[3] Shi Xiang, American Middle School Required Book(Introduction)[Z]. Beijing: Social Sciences Documentation Publishing House, 2001.

[4] Cai Fuqing, Zhu Ziqing Selection (Chapter 2) [Z]. Shijiazhuang: Heibei Education Publishing House, 1989.

[5] Yang Chengsuo, Exploration and Practice of Primary Chinese Education Classical Reading[D]. Shandong: Education Master's thesis of Shandong Nomal University, 2005.

[6] Hu Xiaoming, Enlightment or Uncivilized? [M]. Shanghai: East China Normal University Publishing House, 2006.9

[7] Liu Xiaona, Analyze the Importance of Classical Reading in China from Korean Primary and Middle School Education[J]. Journal of Liaoning School of Education Administration ,2008(9).

[8] See Pitman, M. A.et al., Culture Acqistion: A Holistic Approach to Human learning,1989.

[9] Ogburn, W., Social Change with Respects to Culture and Original Nature,1950. 